\title{
Methodologies and evaluation of electronic travel aids for the visually impaired people: a review
}

\author{
Muhammad Rabani Mohd Romlay ${ }^{1}$, Siti Fauziah Toha ${ }^{2}$, Azhar Mohd Ibrahim $^{3}$, Ibrahim Venkat ${ }^{4}$ \\ 1,2,3 Department Mechatronics Engineering, International Islamic University Malaysia, Malaysia \\ ${ }^{4}$ School of Computing \& Informatics, Universiti Teknologi Brunei, Brunei Darussalam
}

\section{Article Info \\ Article history: \\ Received Sep 29, 2020 \\ Revised Feb 17, 2021 \\ Accepted May 4, 2021}

\section{Keywords:}

Autonomous mobile robot Electronic travel aids LiDAR point cloud

\begin{abstract}
Technological advancements have widely contributed to navigation aids. However, their large-scale adaptation for navigation solutions for visually impaired people haven't been realized yet. Less participation of the visually impaired subject produces a designer-oriented navigation system which overshadows consumer necessity. The outcome results in trust and safety issues, hindering the navigation aids from really contribute to the safety of the targeted end user. This study categorizes electronic travel aids (ETAs) based on experimental evaluations, highlights the designer-centred development of navigation aids with insufficient participation of the visual impaired community. First the research breaks down the methodologies to achieve navigation, followed by categorization of the test and experimentation done to evaluate the systems and ranks it by maturity order. From 70 selected research articles, $51.4 \%$ accounts for simulation evaluation, $24.3 \%$ involve blindfolded-sighted humans, $22.9 \%$ involve visually impaired people and only $1.4 \%$ makes it into production and commercialization. Our systematic review offers a bird's eye view on ETA development and evaluation and contributes to construction of navigational aids which really impact the target group of visually impaired people.
\end{abstract}

This is an open access article under the CC BY-SA license.

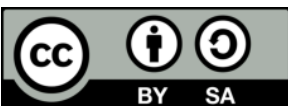

\section{Corresponding Author:}

Muhammad Rabani Mohd Romlay

Department of Mechatronics Engineering

International Islamic University Malaysia

Jalan Gombak, 53100, Kulaa Lumpur, Malaysia

Email: banie91@gmail.com, rabani.romlay@live.iium.edu.my

\section{INTRODUCTION}

For visually impaired people, the most common navigation aid is white canes. While this gives an excellent solution for a near ground obstacle, obstacles which are lower than ground or higher than knee level remain undetected. Difficult circumstances such as crowd disasters [1], road holes and hanging tree branches might also cause problems to blind people. Therefore, researchers are keen to explore scientific advancements which could help the visually impaired community with self-navigating. Mobility aids for visually impaired people known as electronic travel aids (ETAs) are equipped with measurement systems to detect objects and avoid collision [2]. Some of the objectives and challenges of ETA includes detection of obstacle, information on the travel surface, location of landmarks, identification information, selffamiliarization and mapping of the surrounding [3]. Through solid ETA construction, the visually impaired people can be more self-independent, less likely to be involved in accidents, improve their reachability and finally improve the living lifestyle. The objective would be to enable the visually impaired people to travel in a safe and secure condition. 
A. Types of electronic aids

Figure 1 shows the types of ETAs that have been proposed by different researchers. Categorically, ETAs can be grouped into robotic navigation aids (RNA), smartphone-based systems and wearable attachments. RNA is a type of machinery that carries itself [4]. Usually in the form of wheeled robot, it possesses simpler mechanical and dynamics requirements [5]. An active RNA moves on its own, decreasing the burden and preventing the user from exhaustion. Another type of assistive system for the visually impaired is smartphone-based, with image and video processing capability. Wearable attachment systems come in various designs, targeting different body parts for device fitting. Eyeglass, headgear which connected with EEG (electro encephalography) [6]-[8] are some examples of wearable attachment used for navigation.There are pros and cons of each type of ETA. There are pros and cons of each type of ETA. Therefore, it is important to highlight the advantages and disadvantages of different types of ETAs as shown in Table 1.

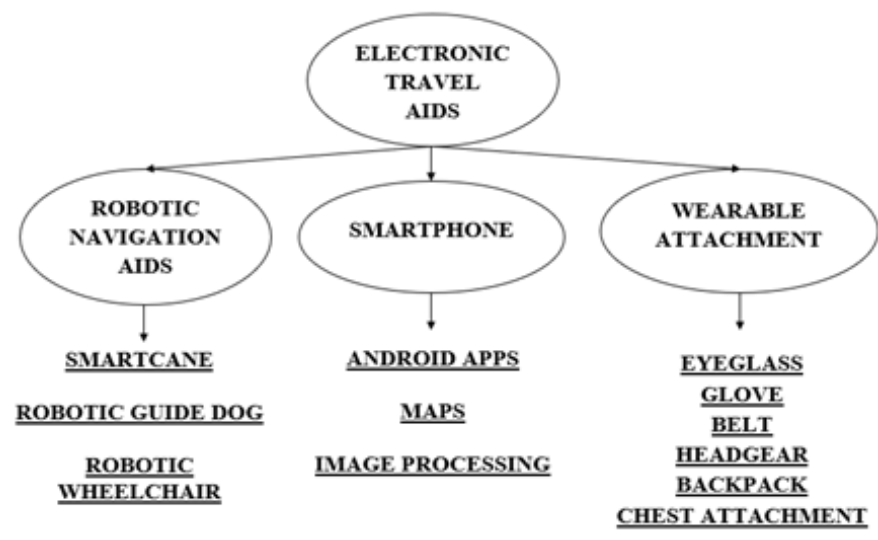

Figure 1. Type of ETAs

Table 1. Advantages and disadvantages of varying ETAs

\begin{tabular}{|c|c|c|c|c|}
\hline & Implementation & Advantages & Disadvantages & Ref \\
\hline \multirow{5}{*}{$\begin{array}{l}\text { Robotic } \\
\text { Navigation } \\
\text { Aids }\end{array}$} & Smart cane & - Offers portability can be used as a normal & - Needs to be compact and & [4] \\
\hline & & white cane should the electronics cease to & lightweight & [9] \\
\hline & & function. & $\begin{array}{l}\text { - Lacks obstacle information } \\
\text { because of restricted sensing } \\
\text { ability offers little information on } \\
\text { wayfinding and navigation } \\
\text { purposes as it requires bigger and } \\
\text { bulkier hardware }\end{array}$ & \\
\hline & $\begin{array}{lr}\text { Robotic } & \text { guide } \\
\text { dog/mobile robot }\end{array}$ & $\begin{array}{l}\text { - The system gives room for larger hardware, } \\
\text { as it does not require a user to carry it }\end{array}$ & $\begin{array}{l}\text { - Complicated mechanicals while } \\
\text { manoeuvring through stairs and } \\
\text { terrain }\end{array}$ & {$[4]$} \\
\hline & $\begin{array}{l}\text { Robotic } \\
\text { wheelchair }\end{array}$ & $\begin{array}{l}\text { - Suitable for the elderly and people who have } \\
\text { a physical limitation provides navigation and } \\
\text { mobility assistance for elderly visually } \\
\text { impaired who cannot walk on their own, } \\
\text { multi-handicapped, or people who have } \\
\text { more than one disabling condition }\end{array}$ & $\begin{array}{l}\text { Safety remains an issue as user } \\
\text { mobility fully depends on the } \\
\text { robotic wheelchair navigation, } \\
\text { road-crossing and stair climbing } \\
\text { are difficult circumstances where } \\
\text { the reliability of the wheelchair is } \\
\text { of extreme necessity }\end{array}$ & [9] \\
\hline Smartphone- & Android apps & - Mobility/portability & - The system depends on sensors & [10] \\
\hline Based System & $\begin{array}{l}\text { Maps } \\
\text { Image } \\
\text { Processing }\end{array}$ & $\begin{array}{l}\text { - No load or invasive factor as the only device } \\
\text { is the smartphone }\end{array}$ & $\begin{array}{l}\text { available on the smartphone. } \\
\text { May communicate with an outer } \\
\text { sensor such as beacon or external } \\
\text { server but then it limits the usage } \\
\text { for indoor requires certain } \\
\text { orientation for image processing or } \\
\text { internet signal for online maps }\end{array}$ & \\
\hline $\begin{array}{l}\text { Wearable } \\
\text { attachment }\end{array}$ & $\begin{array}{l}\text { Eyeglass } \\
\text { Glove } \\
\text { Belt } \\
\text { Headgear } \\
\text { Backpack }\end{array}$ & $\begin{array}{l}\text { - Gives a natural appearance to the visually } \\
\text { impaired user when navigating outdoors }\end{array}$ & $\begin{array}{l}\text { Too much attention is required, } \\
\text { thus giving a cognitive load to the } \\
\text { user these devices are intrusive as } \\
\text { they cover ears and involve the use } \\
\text { of hands users are burdened with } \\
\text { the system's weight. } \\
\text { - Requires a long period of training. }\end{array}$ & $\begin{array}{l}{[4],} \\
{[11]}\end{array}$ \\
\hline
\end{tabular}


As there are pros and cons of each types of ETA, it is up to the designer's approach to choose and build according to their set objectives and requirements. An RNA provides large room for designer's hardware compartment and could provide additional functionality, a smartphone-based system offers mobility and ease of usage for consumers and wearable attachment gives a more natural appearance for users of the visually impaired community.

To form a comprehensive review on ETAs, we investigate the fundamental aspect of ETA build with the methodologies to achieve navigation, and a common ground for ETA's evaluation. This review article investigates the contemporary and current designs of ETA's methodology of achieving navigation and its fraction leading to mobility, then evaluate and classifies the system into a more consumer-centered perspective rather than the commonly designer-oriented innovation, which in results provide in depth insight on how far does the advancement of ETA really impact the core-targeted consumer of the visually impaired community.The rest of the paper is organized as follows: Section 2 describes the work of ETAs on navigation, while section 3 discusses the test and experiment conducted for evaluation. Section 4 provides a discussion on difficulties and challenges faced in ETAs and finally, section 5 concludes the review article and makes recommendations for future researchers. Figure 2 shows the flow chart of the review article from the types of ETA, navigation modules, experiments conducted and finally classifications of the system.

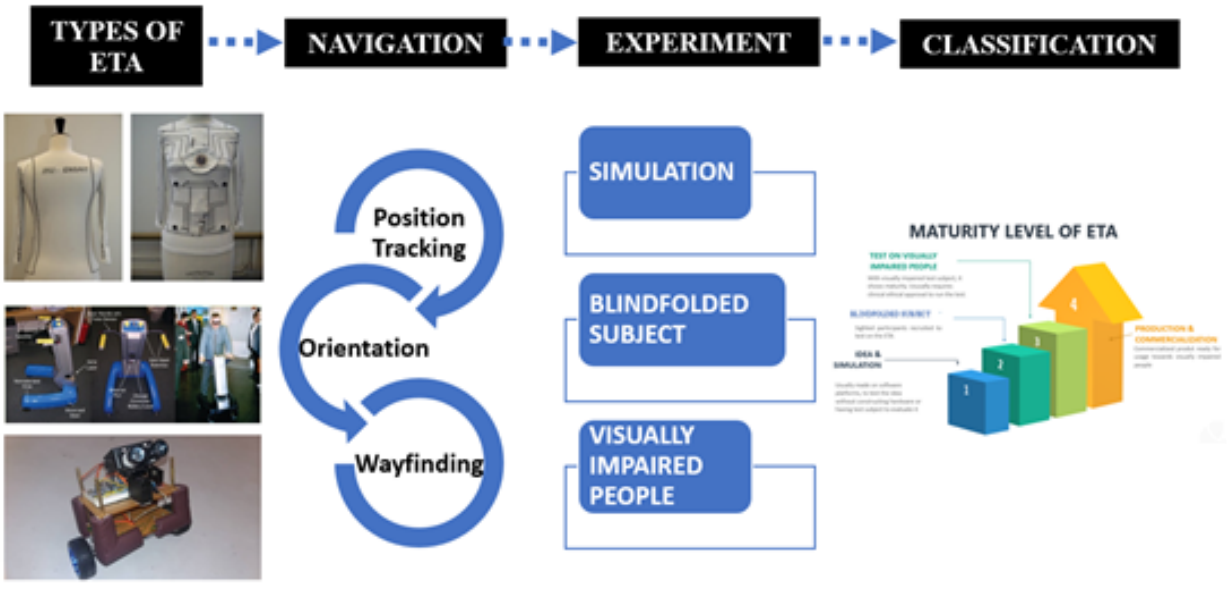

Figure 2. Flowchart of the review article

\section{NAVIGATION}

There are many integral functions which makes up an ETA. Human-machine interface, machinehuman interface, object detection, object recognition, mapping, perception and control of locomotion are some of it just to name a few [3]. However, amongst all functionality, navigation remains as one of the most necessary and fundamental requirement of an ETA system for visual impairment [12].

Navigation is the process of updating one's position and orientation along with a preselected route leading to a destination [13]. Factors such as position tracking, wayfinding and orientation are integral aspects of navigation. The proposed taxonomy chart which classifies the navigation system is shown in Figure 3.

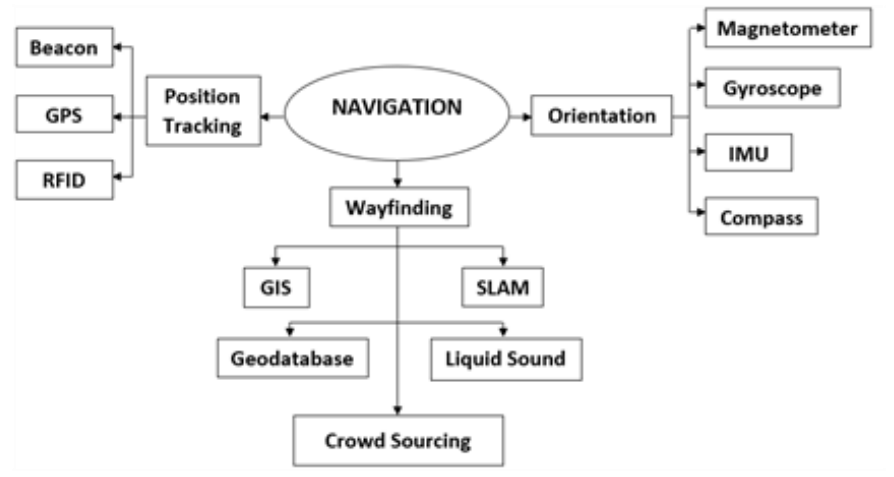

Figure 3. Taxonomy chart of a navigation system 


\subsection{Wayfinding}

Wayfinding deals with the capability to select the correct route from a network of routes starting from an initial point to a destination [13]. It answers the question of "where do I go?" from the visually impaired person's point of view. Other than moving towards destination, wayfinding also includes the action of evacuation [14].

\subsubsection{Crowd sourcing}

One of the methods to achieve wayfinding is through crowdsourcing. An example of crowdsourcing is shown by in [15], where they designed a smartphone application to navigate from point A to B through reliable directions from the online community. A web app of Google App Engine is developed where a sighted user can log on and provide instructions.

\subsubsection{Geodatabase}

Geodatabase, which consists of paths designed for the pedestrian, land-use map, actual video recordings, filed survey and community reports are used in [1], [16], [17]. This key information is then accumulated and amalgamated to form a representation of crossings, sidewalk and real topology of a pedestrian network for users with visual disabilities.

\subsubsection{Geographic information system}

Geographic information system (GIS) with visual landmarks for GIS/vision based localization is discussed in [18]. A camera with a small portable computer such as a netbook is used as its hardware. Incorporation of GPS and GIS for determination of position and orientation for navigation of the visually impaired have also been done. Other implementations of GIS in wayfinding systems include [19], [20]. GIS system may face some difficulties as nature environmental conditions are extremely difficult to measure [21].

\subsection{Orientation}

Orientation is an ability to be aware of one's body position and heading in relation to surrounding objects, cardinal directions and one's location in the followed path [13]. Usually related to rotation of the person's body, it helps in making turns around a corner and keeping the body centre in the pathway. Different types of sensors used to accomplish orientation are discussed in this section.

\subsubsection{Magnetometer}

First, we examine the sensor of magnetometer which are used to estimate heading, measure roll and pitch angles [22]. Salonikidou et al. [23] proposed a system which makes use of a magnetometer for orientation purposes. It determines the heading angle with coordinates stored in GPS as a reference before giving direction command to the user.

\subsubsection{Compass}

A compass is another sensor that can enable orientation awareness. For instance, Skulimowski et al. [24] suggested the point of interest (PoI) explorer mobile application. Making use of an accelerometer and electronic compass within the smartphone, it calculates the angle and orientation of the user relative to the current position and gives direction to the target point. Nonetheless, the system does require a considerable amount of time for utilization, set to be 15 seconds for each complete scan.

\subsubsection{Gyroscope/IMU}

Zheng et al. [25] have estimated the orientation by making use of the gyroscope featured in a smartphone. By solely using a gyroscope, an accurate angle is achieved; with average error of 2.73 within $6 \%$ error rate. Correct altitude is tracked within a short period of 10s. Another sample of navigation assisted by IMU can be seen in [26], [27]. Other than wayfinding, gyroscope sensor is also associated with the ability of balancing and angle determination.

\subsection{Position tracking}

Position tracking or piloting is associated with sensing positional information and using it to determine one's location [28]. One can use an external map or cognitive map to locate oneself relative to the destination. Often referred to by the term localization, it answers the question of "where am I?" for the visually impaired. A well-known predicament, the localization cases are a necessity both within indoor and outdoor situations. 


\subsubsection{Beacon}

First, we examine the use of a beacon to achieve position tracking. Cheragi et al. [29] proposed using low-cost, Bluetooth-based beacon for indoor localization named as GuideBeacon. The GuideBeacon implements received signal strength indicators (RSSI) to estimate user proximity from the sensor. In an experimental phase, the system showed reduced navigation time compared to cane users.

\subsubsection{GPS}

Global positioning system (GPS) is the most commonly used technique for outdoor localization [30]. Chaccour \& Badr [31] have proposed a computer vision-based technique to guide the visually impaired on navigation aspects by making use of the GPS technology and Google maps.

\subsubsection{RFID}

Another method to accomplish position tracking is by using radio-frequency identification (RFID). Costa et al. [32] suggest RFID and computer vision for detection of landmarks placed on the ground. The hardware is equipped with a RFID reader connected via Bluetooth.

\subsection{Discussion on navigation techniques}

Table 2 shows summarizes the navigation techniques of ETAs development with criteria and references. Most commonly devices to achieve navigation purposes are GPS, off-the-shelf smartphone sensors and camerabased system. GPS can be used to attain both wayfinding and path tracking information [33]-[35]. IMU, gyroscope, compass and magnetometer are commonly found in smartphone devices [25], [24]. Camera based wayfinding techniques include SLAM [36], Microsoft Kinect [37]-[39], novel liquid sound navigation [40] and FL20352 camera [41]. Machine learning methods which are getting numerous attention for researchers nowadays [42], [43] such as particle swarm optimization (PSO) [44] have also been implemented for navigation purposes.

Table 2. Summary of navigation methods of ETAs development for visually impaired people

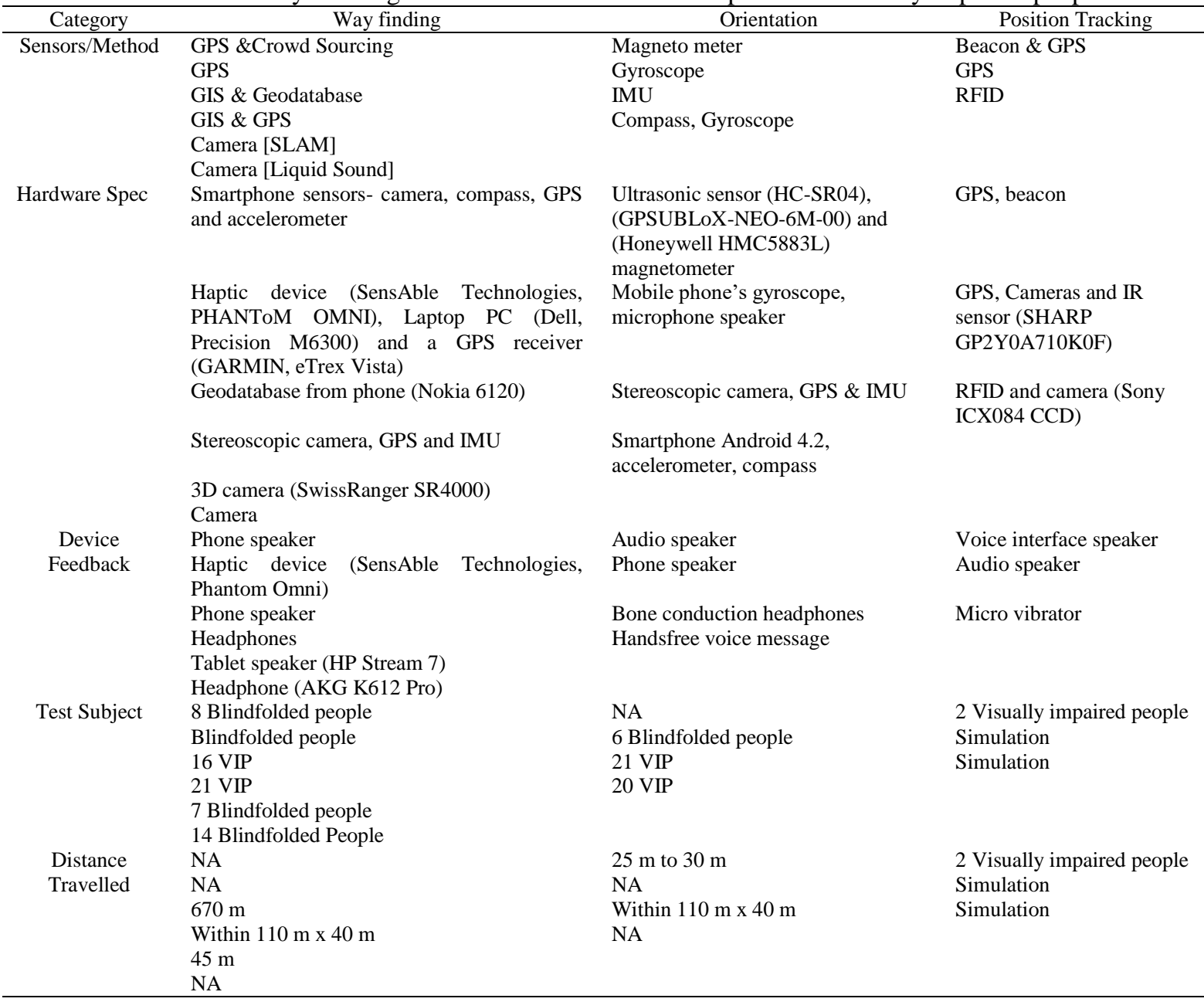


Table 2. Summary of navigation methods of ETAs development for visually impaired people (continue)

\begin{tabular}{|c|c|c|c|}
\hline Category & Way finding & Orientation & Position Tracking \\
\hline \multirow[t]{6}{*}{ Area } & Indoor & Outdoor & Indoor \& outdoor \\
\hline & Outdoor & Indoor \& outdoor & Indoor \& outdoor \\
\hline & Outdoor & Indoor \&outdoor & Indoor \& outdoor \\
\hline & Indoor \& outdoor & Outdoor & \\
\hline & Indoor & & \\
\hline & Indoor & & \\
\hline \multirow[t]{10}{*}{ Test Route } & 1 initial room & 7 location around campus & Straight path with 3 beacons along the \\
\hline & 1 U-turn shaped hallway & & way \\
\hline & 1 destination room & & \\
\hline & $\begin{array}{l}\text { From starting point around a building } \\
\text { to destination }\end{array}$ & $\begin{array}{l}\text { Indoor; hanging TV \& stone wall. } \\
\text { Outdoor; glass wall }\end{array}$ & Object distance from $45 \mathrm{~cm}$ to $325 \mathrm{~cm}$ \\
\hline & 12 segments & Toulose University campus, and & Set of different images were taken on \\
\hline & 13 decision points & district in Toulose center & UTAD campus \\
\hline & 4 pedestrian crossings & & \\
\hline & $\begin{array}{l}\text { Toulouse University campus, and } \\
\text { district in Toulouse center }\end{array}$ & $\begin{array}{l}\text { Area with } 100 \text { Point of Interest, } \\
\text { segmented into smaller section }\end{array}$ & \\
\hline & 7 Points of Interest (PoI) & & \\
\hline & 2 or 3 obstacles & & \\
\hline \multirow{14}{*}{$\begin{array}{c}\text { Evaluation } \\
\text { Criteria }\end{array}$} & - Contact with wall & Arrival to predetermined & - User location evaluation test \\
\hline & - Completion time & destination & - Calculate position of user \\
\hline & $\begin{array}{l}\text { Comparison between concave and } \\
\text { convex haptic representation of the } \\
\text { objects. }\end{array}$ & $\begin{array}{l}\text { - Distance measurement } \\
\text { accuracy } \\
\text { - Wall detection accuracy }\end{array}$ & Object distance error percentage \\
\hline & Error rate & - User travel & Trajectory tracking \\
\hline & - Completion time & - Positioning from GPS & \\
\hline & $\begin{array}{l}\text { - User evaluation on safety, } \\
\text { efficiency \& comfort }\end{array}$ & - Positioning from the system & \\
\hline & - User travel & - Distance to POI & \\
\hline & - Positioning from GPS & - Direction of POI, with & \\
\hline & - Positioning from the system & $\begin{array}{l}\text { orientation relative to user and } \\
\text { destination }\end{array}$ & \\
\hline & - Reach to PoI & & \\
\hline & - Reach to destination & & \\
\hline & - Average time & & \\
\hline & - Collisions with obstacle & & \\
\hline & $\begin{array}{l}\text { - No of subject leaving test area } \\
\text { - Completion time }\end{array}$ & & \\
\hline \multirow[t]{16}{*}{ Result } & Time completion: $67.1 \mathrm{~s}$ & Correction from $224^{\circ}$ degrees to & Accuracy: $90 \%$ \\
\hline & & $280^{\circ}$ degrees & $\begin{array}{l}\text { Average distance error: } 0.47 \mathrm{~m} \text { Distance } \\
\text { error: } 0.1 \mathrm{~m} \text { or } 0.2 \mathrm{~m} \text { Low severity } \\
\text { (neglected error) for the navigation } \\
\text { system. }\end{array}$ \\
\hline & Average contact: 0.25 & Error rate: $6 \%$ & Absolute error: $3.8 \% \sim 1.72 \%$. Error \\
\hline & & Average angle error: $2.73^{\circ}$ & $\begin{array}{l}\text { minimal when the distance to the object } \\
\text { is } 3 \mathrm{~m}\end{array}$ \\
\hline & Based on user evaluation. & Better positioning given by the & The trajectory correction is computed, \\
\hline & Comfortability: $33 \%$ agreed & system compared to GPS and & and output is given to blind target \\
\hline & Efficiency: $50 \%$ agreed & improved user navigation & \\
\hline & Safety: $33 \%$ agreed & & \\
\hline & Better positioning given by the system & Time of application: $15 \mathrm{~s}$ & \\
\hline & compared to GPS only and improved & System accuracy decrease with & \\
\hline & user navigation & higher number of POI. & \\
\hline & System identify PoI: 95\% & & \\
\hline & Percentage of users arrive at & & \\
\hline & destination: $81 \%$ End Point Position & & \\
\hline & Error Norm (EPEN): $0.29 \mathrm{~m}$ & & \\
\hline & $\begin{array}{l}\text { Percentage of completed scene: } 76 \% \\
{[15],[16],[27],[36],[40],[45]}\end{array}$ & [24] [ 25], [27] [46] & [30], [32] [33] \\
\hline Ne1 & {$[10],[10],[21],[30],[10],[10]$} & {$[2-T],[20],[21],[70]$} & {$[30],[32],[33]$} \\
\hline
\end{tabular}

\section{TESTS AND EXPERIMENT}

Test and experiment are done on ETAs to evaluate the system, acting as a benchmark for the prototype's real-life usage. We categorised test and experiments done on ETAs into 3 categories; simulation based, blindfolded-sighted people and visually impaired person.

\subsection{Simulation}

Initially, experiments to evaluate ETAs are done by simulation. One of the early simulation tests for visually impaired technology with stereo vision-based aid is presented in [47]. They tested the ground plane 
obstacle detection (GPOD) algorithm using a pair of cameras to simulate an image sequence of the real outdoor scene. Meanwhile, Karacs et al. [48] established a database for training and testing algorithms develop for bionic eyeglass; cell phone and camera-based image recognition system. A database of 200 videos with lengths of 10 to 90 seconds of indoor and outdoor recordings are taken from visually impaired persons. Nandini \& Seeja [49] tested an algorithm for path planning within a supermarket environment with $\mathrm{C}++$ simulation. A supermarket layout with numbered corners and section as point of interest (PoI) is mapped out on the system. Desired destination and current situation are given as the input from the user.

\subsection{Blindfolded-sighted people}

The second way of experiment is by having the ETA tested by blindfolded subjects. Several tests require the examinee to walk down a set of routes which resemble a real-life scenario, including walking within a pre-arranged pathway around indoor environment or outdoor surroundings. Table 3 shows some of the evaluation with a blindfolded examinee with varying numbers of the test subject, test route surroundings and evaluation criteria. The method of experiment using a blindfolded-sighted human subject can be considered as an intermediate technique in between simulation and using a real visually impaired people for testing. It is a more realistic way of experiment when compared to simulation-based testing but is less effective to really grasp the feeling and opinion of a visually impaired subject. In terms of difficulty, it is also in between simulation and using visually impaired as it involves human subject but depreciate of the necessity of the safety precautions and issues required of involving a real blind people subject.

Table 3. ETAs development tested by blindfolded sighted human subject

\begin{tabular}{|c|c|c|c|c|c|}
\hline Ref & Distance & Indoor/Outdoor & Route/Obstacle & Evaluation criteria & $\begin{array}{r}\text { Test Subject } \\
\text { (blind-folded) }\end{array}$ \\
\hline [50] & na & Indoor & 4 cycle around a trail & $\begin{array}{l}\text { Time taken/No of contact on obstacle/Densities of } \\
\text { vibration motor/No of vibration/Vibration motor } \\
\text { allocation }\end{array}$ & 49 \\
\hline [40] & na & Indoor & 2 or 3 obstacles & $\begin{array}{l}\text { Collisions with obstacle/Number of leaving } \\
\text { testing area/Completion time }\end{array}$ & 14 \\
\hline [31] & na & Indoor & $\begin{array}{l}1 \text { kitchen } / 1 \text { living } \\
\text { room } / 1 \text { bedroom }\end{array}$ & $\begin{array}{l}\text { Object search ability/Ability to provide path } \\
\text { navigation }\end{array}$ & 8 \\
\hline [15] & na & Indoor & $\begin{array}{l}1 \text { initial room } / 1 \mathrm{U} \text {-turn } \\
\text { shaped hallway/ } 1 \\
\text { destination room } \\
4 \text { doorways } 4\end{array}$ & Contact with wall/Completion time & 8 \\
\hline [51] & na & Indoor & $\begin{array}{l}\text { hallways } / 2 \text { downward } \\
\text { stairways }\end{array}$ & Object recognition accuracy & 7 \\
\hline [36] & $45 \mathrm{~m}$ & Indoor & $\begin{array}{l}7 \text { Points of Interest } \\
\text { (PoI) }\end{array}$ & Reach to PoI/Reach to destination/Average time & 7 \\
\hline [52] & na & $\begin{array}{l}\text { Indoor \& } \\
\text { outdoor }\end{array}$ & $\begin{array}{l}\text { Indoor; chairs and } \\
\text { ventilators. } \\
\text { Outdoor; bicycles, cars, } \\
\text { bushes and pedestrians }\end{array}$ & $\begin{array}{l}\text { Mental demand/Physical demand/Temporal } \\
\text { demand/Performance/Effort/Frustration }\end{array}$ & 6 \\
\hline [25] & na & $\begin{array}{l}\text { Indoor \& } \\
\text { outdoor }\end{array}$ & $\begin{array}{l}\text { Indoor; hanging TV \& } \\
\text { stone wall. } \\
\text { Outdoor; glass wall }\end{array}$ & $\begin{array}{l}\text { Distance measurement accuracy/Wall detection } \\
\text { accuracy }\end{array}$ & 6 \\
\hline [9] & $\begin{array}{l}20 \mathrm{~m} \sim 40 \\
\mathrm{~m}\end{array}$ & Indoor & Looped trajectory & $\begin{array}{l}\text { Final position error/Error reduction/Dead } \\
\text { reckoning/Object recognition }\end{array}$ & 5 \\
\hline [53] & $32 \mathrm{~m}$ & Indoor & office room to a stair & Walking errors/Travelling time & 4 \\
\hline [54] & $10 \mathrm{~m}$ & Indoor & $\begin{array}{l}5 \text { obstacles along the } \\
\text { way }\end{array}$ & Travel speed/Cleared obstacle & 3 \\
\hline
\end{tabular}

\subsection{Visually impaired person}

The third method of evaluating ETA is by testing the device with visually impaired people. Having visually impaired as an experimental subject requires more safety measures and requirements. A clinical or ethical approval to run the test is compulsory before attempting to recruit a visually impaired person examinee. Table 4 shows the ETAs development which has been tested or evaluated by visually impaired people.

Table 4. ETAs evaluation test with the visually impaired people

\begin{tabular}{|c|c|c|c|c|c|c|}
\hline \multirow{2}{*}{ Ref } & \multirow{2}{*}{ Distance } & \multirow{2}{*}{ Indoor/Outdoor } & \multirow{2}{*}{ Route Surrounding } & \multirow{2}{*}{ Evaluation criteria } & \multicolumn{2}{|c|}{ Test Subject } \\
\hline & & & & & V.I.P & Blindfolded \\
\hline$[55]$ & $33.4 \mathrm{~m}$ & Outdoor & $\begin{array}{l}3 \text { turning point } / 3 \text { pedestrian } \\
\text { overpasses } / 2 \text { tress obstruction } / 2 \text { parked } \\
\text { motorcycle } / 1 \text { side door } / 1 \text { plant } \\
\text { terrace } / 1 \text { cardboard box }\end{array}$ & $\begin{array}{l}\text { Finishing time/Collision } \\
\text { frequency Most collided } \\
\text { obstacle/Parts of the body in } \\
\text { contact }\end{array}$ & 15 & 5 \\
\hline
\end{tabular}


Table 4. ETAs evaluation test with the visually impaired people (continue)

\begin{tabular}{|c|c|c|c|c|c|c|}
\hline \multirow{2}{*}{ Ref } & \multirow{2}{*}{ Distance } & \multirow{2}{*}{ Indoor/Outdoor } & \multirow{2}{*}{ Route Surrounding } & \multirow{2}{*}{ Evaluation criteria } & \multicolumn{2}{|c|}{ Test Subject } \\
\hline & & & & & V.I.P & Blindfolded \\
\hline [56] & $\begin{array}{l}1.2 \mathrm{~m} \\
3.5 \mathrm{~m}\end{array}$ & Indoor & $\begin{array}{l}3 \text { persons in front of user to be } \\
\text { recognized }\end{array}$ & $\begin{array}{l}\text { Face recognition accuracy/User } \\
\text { evaluation }\end{array}$ & 5 & 9 \\
\hline [10] & $\begin{array}{c}5 \mathrm{~m} \times 7 \\
\mathrm{~m}\end{array}$ & Indoor & $4 \mathrm{room} / 1$ entrance/ 1 exit & $\begin{array}{l}\text { Exploration time/Navigate/Layout } \\
\text { recognition \& representation }\end{array}$ & 5 & 20 \\
\hline [23] & $\underset{\mathrm{m}}{10 \mathrm{~m} \times 7}$ & Indoor & 3 obstacles along the way & $\begin{array}{l}\text { Navigation time/User evaluation on } \\
\text { familiarity }\end{array}$ & 5 & 11 \\
\hline [57] & na & Indoor & $\begin{array}{l}\text { Sunroom/smoking } \\
\text { room/dining room/main } \\
\text { entrance }\end{array}$ & $\begin{array}{l}\text { Time completion/Force on } \\
\text { handlebar/Number of collisions }\end{array}$ & 2 & - \\
\hline [16] & $670 \mathrm{~m}$ & Outdoor & $\begin{array}{l}12 \text { segments/ } 13 \text { decision } \\
\text { points } / 4 \text { pedestrian crossings }\end{array}$ & $\begin{array}{l}\text { Error rate/Completion time/User } \\
\text { evaluation on safety, efficiency and } \\
\text { comfort }\end{array}$ & 16 & - \\
\hline [29] & $\begin{array}{l}50-300 \\
\text { steps }\end{array}$ & Indoor & $\begin{array}{l}\text { beacon } 7 \text { to } 0 \text { situated on upper } \\
\text { floor, northwest from entrance }\end{array}$ & $\begin{array}{l}\text { Navigation time/Distance/User } \\
\text { evaluation }\end{array}$ & 7 & 1 \\
\hline [58] & 4.6 miles & Outdoor & $\begin{array}{l}10 \text { metro stations } / 2 \text { different } \\
\text { metro network lines }\end{array}$ & $\begin{array}{l}\text { Choosing metro station/Changing } \\
\text { between metro lines/Arrival to } \\
\text { destination }\end{array}$ & 10 & - \\
\hline
\end{tabular}

\section{DIFFICULTIES AND CHALLENGES IN ETAS BUILDUP}

Figure 4 shows the maturity level inherent on the development of ETAs, categorically classified from simulation, tested on blindfolded subject, test on visually impaired. The final goal would be production and commercialization for end users. Table 5 shows the maturity level of ETAs development in selected reviewed research papers. Out of 70 related research articles only one exceptional product was successfully commercialized. The development of GUIDO, a smart walker for the blind [57] has seen success in preproduction unit sales to the U.S. Department of Veterans Affairs. There is an obvious trend of ETA constructions to be abbreviated the further they progress through the maturity stages. Therefore, it is of monumental importance to study the factors which hinder the progress of ETAs.

\section{MATURITY LEVEL OF ETA}

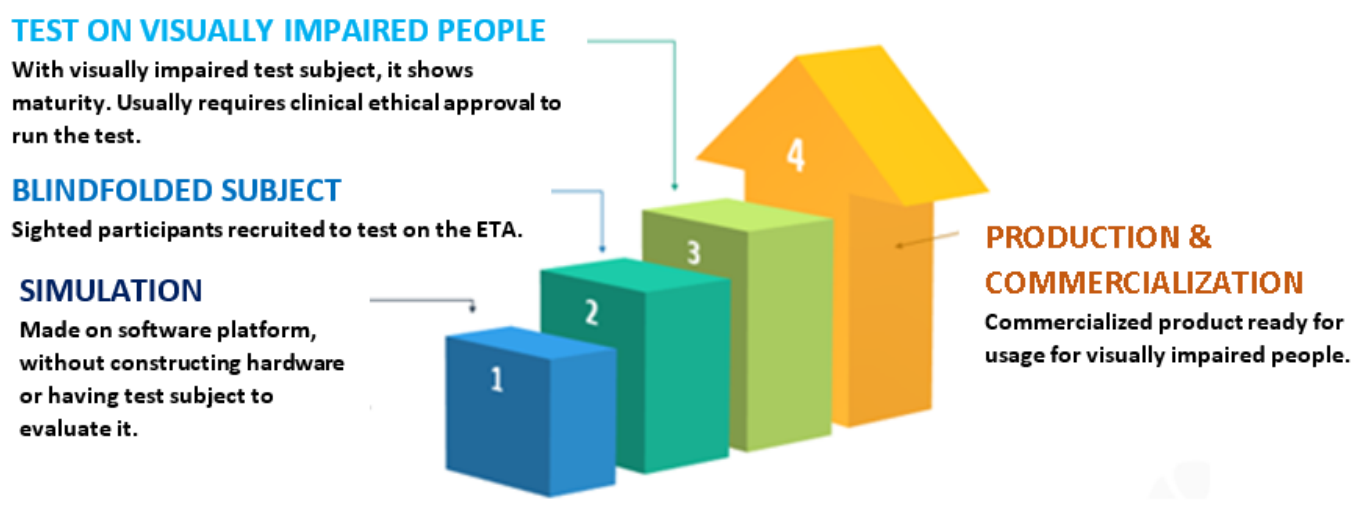

Figure 4. Maturity level of ETAs

Table 5. Maturity level of ETAs development

\begin{tabular}{ccc}
\hline Maturity Level of ETA Development & No of research articles & Percentage \% (out of 70 research articles) \\
\hline Simulation & 36 & $51.4 \%$ \\
Blindfolded Subject & 17 & $24.3 \%$ \\
Visually Impaired Subject & 16 & $22.9 \%$ \\
Production \& Commercialization & 1 & $1.4 \%$ \\
\hline
\end{tabular}

The first key factor which challenges the commercialization of ETAs is the market acceptance of new technology. Safety issues and concern remains an issue for the visually impaired community. However, with significant effort the sceptical mindset towards robotic machinery which hinders the progress of navigation technology can be eliminated. Researchers also claim that the user is not resistant towards adaptation of robotic technology if it can deliver benefits in their daily living [57]. 
The second obstruction to ETA's commercialization lies within the complex production and testing systems. Ethical approval, and recognition by clinical bodies and organizations are a must, such as the food and drug administration (FDA) in the United States. And in order to acquire clinical validity, large and well defined patient groups are needed as evidence of safety aspects of the development [59]. Therefore, more involvement and participation from each contributing party is necessary, including designers (engineers), authorities (doctors and clinicians) and the end users (visually impaired community).

The third factor are designed methodologies which lack user-centred philosophy and requirements. There are many cases where sophisticated innovations of the designer's concept overshadow consumer necessity. Therefore, an intensive effort must be made to see more collaboration between engineering designers, medical clinicians and visually impaired users to make the product more consumer-oriented and user-centred. There should also be a clear-cut objective which is to prioritize the needs of the visually impaired people at all costs.

\section{CONCLUSION \& FUTURE WORKS}

This review paper has thoroughly discussed the fundamentals of ETA construction with the main objective of navigation and its components of wayfinding, orientation and position tracking. The evaluation stages of simulation, human subject tests and commercialization have been presented to assess the technology readiness level. This review article has presented the layout of advantages and disadvantages of each types of ETA, the methodologies of achieving the ETA's most fundamental functionality namely the process of navigation, capacity and capability of varieties of sensors to achieve fractions of navigation in orientation, wayfinding and position tracking, test and experiments done on evaluating the ETA's designed and finally classification of current ETA's level of maturity. We perceive that such purposefully set objectives could give future researchers a benchmark for experimentation, and act as a blueprint of future ETA evaluation. In a nutshell, the highlights of our review paper are:

- Breakdown of types of ETA and its advantages and disadvantages. The navigation techniques of ETA are then divided into position tracking, wayfinding and orientation methodology, with further study on its sensor's selection, and finally assessment on its capacity and capability of moving the visually impaired towards its destination.

- Results of ETA test and experiment, comparison on its level of readiness and overview of fraction of methods of evaluation; namely simulation, experiment done on sighted blindfolded subject and experiment done with real visually impaired subject.

- Classification of current ETA's development into levels of maturity, providing an eagle eye view of impacts of ETA towards the targeted subject of the visually impaired community as a whole.

For future work, it would be interesting to see further investigation done from experts of the medical field or clinicians to assess ETAs. This would open the doors to consumer-centred concepts and diminish designer-oriented designs that we have at the present time. The core ideas assimilated in this research could serve as a benchmark for future research projects relevant to ETA evaluation. Through this review, we perceived that the future developers would be encouraged to have a better communication with physicians and the medical side of the system's requirement, and to have a better understanding of the visually impaired people as the intended consumer of the developed product.

\section{ACKNOWLEDGEMENTS}

The research is funded by grant number SRCG20-046-0046 IoT-Based visually impaired community (VIC) Geospatial Tracking with Swarming RoVision (SR), UMP-IIUM-UiTM Sustainable Research Collaboration 2020 and IRAGS18-014-0015 from International Islamic University Malaysia (IIUM).

\section{REFERENCES}

[1] A. M. Ibrahim, I. Venkat, and P. De Wilde, "The Impact of Potential Crowd Behaviours on Emergency Evacuation: An Evolutionary Game-Theoretic Approach," Journal of Artificial Societies and Social Simulation (JASS), vol. 22, no. 1, pp. 1-15, 2019, doi: 10.18564/jasss.3837.

[2] U. Röijezon, M. Prellwitz, D. I. Ahlmark, J. van Deventer, G. Nikolakopoulos, and K. Hyyppä, "A Haptic Navigation Aid for Individuals with Visual Impairments: Indoor and Outdoor Feasibility Evaluations of the LaserNavigator," Journal of Visual Impairment \& Blindness, vol. 113, no. 2, pp. 194-201, 2019, doi: $10.1177 / 0145482 \times 19842491$

[3] E. Cardillo and A. Caddemi, "Insight on Electronic Travel Aids for Visually Impaired People : A Review on the Electromagnetic Technology," Electronics, vol. 8, no. 11, 2019, Art. no. 1281, doi: 10.3390/electronics8111281. 
[4] H. Ogawa, K. Tobita, K. Sagayama, and M. Tomizuka, "A Guidance Robot for the Visually Impaired: System Description and Velocity Reference Generation," 2014 IEEE Symposium on Computational Intelligence in Robotic Rehabilitation and Assistive Technologies (CIR2AT), 2014, pp. 9-15, doi: 10.1109/CIRAT.2014.7009735.

[5] M. R. M. Romlay, M. I. Azhar, S. F. Toha, and M. M. Rashid, "Two-wheel Balancing Robot ; Review on Control Methods and Experiment," International Journal of Recent Technology and Engineering (IJRTE), vol. 7, no. 6S, pp. 106-112, 2017.

[6] K. R. Sravanth, A. Peddi, G. S. Sagar, B. Gupta, and C. Chakraborty, "Comparison of Attention and Meditation based mobile applications by using EEG signals," 2018 Global Wireless Summit (GWS), 2018, pp. 260-265, doi: 10.1109/GWS.2018.8686634.

[7] M. Sameer, A. K. Gupta, C. Chakraborty, and B. Gupta, "Epileptical Seizure Detection : Performance analysis of gamma band in EEG signal Using Short-Time Fourier Transform," 2019 22nd International Symposium on Wireless Personal Multimedia Communications (WPMC), 2019, vol. 22, pp. 1-6, doi: 10.1109/WPMC48795.2019.9096119.

[8] S. K. Ramakuri, C. Chakraborty, S. Ghosh, and B. Gupta, "Performance Analysis of Eye-State Charecterization through Single Electrode EEG Device for Medical Application," 2017 Global Wireless Summit (GWS), 2017, pp. 1-6, doi: 10.1109/GWS.2017.8300494.

[9] C. Ye, S. Hong, X. Qian, and W. Wu, "A New Robotic Navigation Aid for the Visually Impaired," IEEE Systems, Man \& Cybernetics Magazine, vol. 2, no. 2, pp. 33-42, 2016, doi :10.1109/MSMC.2015.2501167.

[10] E. E. Pissaloux, R. Velázquez, and F. Maingreaud, "A New Framework for Cognitive Mobility of Visually Impaired Users in Using Tactile Device," IEEE Transactions on Human-Machine Systems, vol. 47, no. 6, pp. 1040-1051, 2017, doi: 10.1109/THMS.2017.2736888.

[11] S. K. Bahadir, V. Koncar, and F. Kalaoglu, "Wearable Obstacle Detection System Fully Integrated to Textile Structures for Visually Impaired People," Sensors and Actuators, A: Physical, vol. 179, pp. 297-311, 2012, doi: 10.1016/j.sna.2012.02.027.

[12] M. Bousbia-Salah, M. Bettayeb, and A. Larbi, "A Navigation Aid for Blind People," Journal of Intelligent \& Robotic Systems, vol. 64, no. 3-4, pp. 387-400, 2011, doi: 10.1007/s10846-011-9555-7.

[13] P. Strumillo, "Electronic Interfaces Aiding the Visually Impaired in Environmental Access, Mobility and Navigation," 3rd International Conference on Human System Interaction, 2010, pp. 17-24, doi: 10.1109/HSI.2010.5514595

[14] A. M. Ibrahim, M. Saifullah, M. R. M. Romlay, I. Venkat, and I. Ibrahim, "Hybrid Social Force-Fuzzy Logic Evacuation Simulation Model For Multiple Exits," 2019 7th International Conference on Mechatronics Engineering (ICOM), 2019, no. 7th, pp. 1-5, doi: 10.1109/ICOM47790.2019.8952063.

[15] G. Olmschenk, C. Yang, Z. Zhu, H. Tong, and W. H. Seiple, "Mobile Crowd Assisted Navigation for The Visually Impaired," 2015 IEEE 12th Intl Conf on Ubiquitous Intelligence and Computing and 2015 IEEE 12th Intl Conf on Autonomic and Trusted Computing and 2015 IEEE 15th Intl Conf on Scalable Computing and Communications and Its Associated Workshops (UIC-ATC-ScalCom), 2015, pp. 324-327, doi: 10.1109/UIC-ATC-ScalComCBDCom-IoP.2015.69.

[16] J. Balata, Z. Mikovec, P. Bures, and E. Mulickova, "Automatically Generated Landmark-enhanced Navigation Instructions for Blind Pedestrians," 2016 Federated Conference on Computer Science and Information Systems (FedCSIS), 2016, vol. 8, pp. 1605-1612, doi: 10.15439/2016F135

[17] A. Mohd Ibrahim, I. Venkat, and P. De Wilde, "Uncertainty in a Spatial Evacuation Model," Physica A: Statistical Mechanics and its Applications, vol. 479, pp. 485-497, 2017, doi: 10.1016/j.physa.2017.03.024

[18] M. Serrão, J. M. F. Rodrigues, J. I. Rodrigues, and J. M. H. Du Buf, "Indoor Localization and Navigation for Bind Persons Using Visual Landmarks and a GIS," Procedia Computer Science, vol. 14, pp. 65-73, 2012, doi: 10.1016/j.procs.2012.10.008.

[19] W. Dong, T. Qin, H. Liao, Y. Liu, and J. Liu, "Comparing the roles of landmark visual salience and semantic salience in visual guidance during indoor wayfinding," Cartography and Geographic Information Science, vol. 47, no. 3, pp. 229-243, 2020, doi: 10.1080/15230406.2019.1697965.

[20] H. Iftikhar, P. Shah, and Y. Luximon, "Human wayfinding behaviour and metrics in complex environments : a systematic literature review," Architectural Science Review, pp. 1-12, 2020, doi: 10.1080/00038628.2020.1777386.

[21] M. M. Rashid, M. R. M. Romlay, and M. M. Ferdaus, "Development of Electronic Rain Gauge System," International Journal of Electronics and Electrical Engineering (IJEEE), vol. 3, no. 4, pp. 245-249, 2015, doi: 10.12720/ijeee.3.4.245-249.

[22] P. Taylor, V. Renaudin, M. H. Afzal, and G. Lachapelle, "Magnetic Perturbations Detection and Heading Estimation Using Magnetometers," Journal of Location Based Services, vol. 6, no. 3, pp. 161-185, 2012, doi: 10.1080/17489725.2012.698109.

[23] B. Salonikidou, D. Savvas, G. Diamantis, and A. Astaras, "Development and Evaluation of an Open Source Wearable Navigation Aid for Visually Impaired Users (CYCLOPS)," 2012 IEEE 12th International Conference on Bioinformatics \& Bioengineering (BIBE), 2012, pp. 115-120, doi: 10.1109/BIBE.2012.6399659.

[24] P. Skulimowski, P. Korbel, and P. Wawrzyniak, "POI explorer-A Sonified Mobile Application Aiding the Visually Impaired in Urban Navigation," 2014 Federated Conference on Computer Science and Information Systems, 2014, vol. 2, pp. 969-976, doi: 10.15439/2014F293.

[25] Z. Zheng, W. Liu, R. Ruby, Y. Zou, and K. Wu, "ABAid: Navigation Aid for Blind People Using Acoustic Signal," 2017 IEEE 14th International Conference on Mobile Ad Hoc and Sensor Systems (MASS), 2017, pp. 333-337, doi: 10.1109/MASS.2017.37 
[26] S. Sakhi, A. Elouardi, S. Bouaziz, and M. Belhocine, "Vehicle Localization Systems: Towards Low-Cost Architectures," Turkish Journal of Electrical Engineering \& Computer Sciences, vol. 24, no. 4, pp. 2010-2027, 2016, doi: 10.3906/elk-1402-260

[27] S. Kammoun, G. Parseihian, O. Gutierrez et al., "Navigation and Space Perception Assistance for The Visually Impaired: The NAVIG Project," IRBM, vol. 33, no. 2, pp. 182-189, 2012, doi: 10.1016/j.irbm.2012.01.009.

[28] J. M. Loomis, R. G. Golledge, R. L. Klatzky, and J. R. Marston, "Assisting Wayfinding in Visually Impaired Travelers," Applied Spatial Cognition., Edition 1 ${ }^{\text {st }}$, 2007, doi: 10.4324/9781003064350-7.

[29] S. A. Cheraghi, V. Namboodiri, and L. Walker, "GuideBeacon: Beacon-based Indoor Wayfinding For the Blind, Visually Impaired, and Disoriented," 2017 IEEE International Conference on Pervasive Computing and Communications (PerCom), 2017, pp. 121-130, doi: 10.1109/PERCOM.2017.7917858

[30] J. Cecílio, K. Duarte, and P. Furtado, "BlindeDroid: An Information Tracking System for Real-time Guiding of Blind People," Procedia Computer Science, vol. 52, pp. 113-120, 2015, doi: 10.1016/j.procs.2015.05.039

[31] K. Chaccour and G. Badr, "Computer Vision Guidance System for Indoor Navigation of Visually Impaired People," 2016 IEEE 8th International Conference on Intelligent Systems (IS), 2016, pp. 449-454, doi: 10.1109/IS.2016.7737460

[32] P. Costa, H. Fernandes, P. Martins, J. Barroso, and L. J. Hadjileontiadis, "Obstacle Detection Using Stereo Imaging to Assist the Navigation of Visually Impaired People," Procedia Computer Science, vol. 14, pp. 83-93, 2012, doi: 10.1016/j.procs.2012.10.010.

[33] P. S. Ranaweera, S. H. R. Madhuranga, H. F. A. S. Fonseka, and D. M. L. D. Karunathilaka, "Electronic Travel Aid System for Visually Impaired People," 2017 5Th International Conference on Information and Communication Technology (Icoic7), 2017, pp. 1-6, doi: 10.1109/ICoICT.2017.8074700

[34] S. A. Zulkiflie, N. Kamaruddin, and A. Wahab, "Dynamic navigation indoor map using Wi-Fi fingerprinting mobile technology," Bulletin of Electrical Engineering and Infromatics (BEEI), vol. 9, no. 2, pp. 739-746, 2020, doi: 10.11591/eei.v9i2.2066.

[35] K. A. F. A. Samah, S. Ibrahim, N. Ghazali, M. Suffian, M. Mansor, and W. A. Latif, "Mapping a hospital using OpenStreetMap and Graphhopper: A navigation system," Bulletin of Electrical Engineering and Infromatics (BEEI), vol. 9, no. 2, pp. 661-668, 2020, doi: 10.11591/eei.v9i2.2082.

[36] H. Zhang and C. Ye, "An Indoor Navigation Aid for the Visually Impaired," 2016 IEEE International Conference on Robotics and Biomimetics (ROBIO), 2016, pp. 467-472, doi: 10.1109/ROBIO.2016.7866366

[37] B. Kuriakose, R. Shrestha, and F. E. Sandnes, "Tools and Technologies for Blind and Visually Impaired Navigation Support: A Review Tools and Technologies for Blind and Visually Impaired Navigation Support," IETE Technical Review, pp. 1-16, 2020, doi: 10.1080/02564602.2020.1819893.

[38] E. I. A. L. Khatib, M. Abdel, K. Jaradat, M. F. Abdel-hafez, "Low-Cost Reduced Navigation System for Mobile Robot in Indoor/Outdoor Environments," IEEE Access, vol. 8, pp. 25014-25026, 2020, doi: 10.1109/ACCESS.2020.2971169

[39] J. R. Alayon, V. G. D. Corciega, N. M. L. Genebago, A. B. A. Hernandez, C. R. C. Labitoria, and R. E. Tolentino, "Design of Wearable Wrist Haptic Device for Blind Navigation using Microsoft Kinect for Xbox 360," 2020 4th International Conference on Trends in Electronics and Informatics (ICOEI), 2020, pp. 1005-1010, doi: 10.1109/ICOEI48184.2020.9143005

[40] S. Spagnol, R. Hoffmann, M. Herrera, and R. Unnthorsson, "Blind Wayfinding with Physically-based Liquid Sounds," International Journal of Human - Computer Studies, vol. 115, pp. 9-19, 2018, doi: 10.1016/j.ijhcs.2018.02.002

[41] L. D. Dunai, I. L. Lengua, I. Tortajada, and F. B. Simon, "Obstacle Detectors for Visually Impaired People," 2014 International Conference on Optimization of Electrical and Electronic Equipment, OPTIM 2014, no. 1975, pp. 809-816, 2014, doi: 10.1109/OPTIM.2014.6850903

[42] M. R. M. Romlay, M. M. Rashid, and S. F. Toha, "Development of Particle Swarm Optimization Based RainfallRunoff Prediction Model for Pahang River, Pekan,” 2016 International Conference on Computer and Communication Engineering (ICCCE), 2016, pp. 306-310, doi: 10.1109/ICCCE.2016.72.

[43] M. R. M. Romlay, M. M. Rashid, and S. F. Toha, "Rainfall-Runoff Model Based on ANN with LM , BR and PSO as Learning Algorithms," International Journal of Recent Technology and Engineering (IJRTE), vol. 8, no. 3, pp. 971-979, 2019, DOI:10.35940/ijrte.C4115.098319.

[44] S. F. Toha, H. Yusof, M. F. Razali, and A. Hadi, "Intelligent Path Guidance Robot for Blind Person Assistance," 2015 International Conference on Informatics, Electronics \& Vision (ICIEV), 2015, doi: 10.1109/ICIEV.2015.7334040.

[45] T. Satoi, M. Koeda, and T. Yoshikawa, "Virtual Haptic Map Using Force Display Device for Visually Impaired," IFAC Proceedings Volumes, vol. 42, no. 16, pp. 645-650, 2009, doi: 10.3182/20090909-4-JP-2010.00109

[46] N. B. James and A. Harsola, "Navigation Aiding Stick for the Visually Impaired," 2015 International Conference on Green Computing and Internet of Things (ICGCIoT), 2015, pp. 1254-1257, doi: 10.1109/ICGCIoT.2015.7380656

[47] N. Molton, S. Se, J. M. Brady, D. Lee, and P. Probert, "A Stereo Vision-based Aid for the Visually Impaired," Image and Vision Computing, vol. 16, no. 4, pp. 251-263, 1998, doi: 10.1016/S0262-8856(97)00087-5.

[48] K. Karacs, A. Lazar, R. Wagner, B. Balint, T. Roska, and M. Szuhaj, "Bionic Eyeglass: The First Prototype A personal Navigation Device for Visually Impaired - A Review," 2008 1st International Symposium on Applied Sciences in Biomedical and Communication Technologies, ISABEL 2008, 2008, pp. 1-5, doi: 10.1109/ISABEL.2008.4712625.

[49] D. Nandini and K. R. Seeja, "A Novel Path Planning Algorithm for Visually Impaired People," Journal of King Saud University - Computer and Information Sciences, vol. 31, no. 3, pp. 385-391, 2017, doi: 10.1016/j.jksuci.2017.03.005.

[50] M. R. Adame, J. Yu, K. Moller, and E. Seemann, "A Wearable Navigation Aid for Blind People using a Vibrotactile Information Transfer System," 2013 ICME International Conference on Complex Medical Engineering, pp. 13-18, 2013, doi: 10.1109/ICCME.2013.6548203 
[51] C. Ye and X. Qian, "3-D Object Recognition of a Robotic Navigation Aid for the Visually Impaired," IEEE Transaction on Neural Systems and Rehabilitation Engineering, vol. 26, no. 2, pp. 441-450, 2018, doi: 10.1109/TNSRE.2017.2748419.

[52] M. Martinez, A. Roitberg, D. Koester, R. Stiefelhagen, and B. Schauerte, "Using Technology Developed for Autonomous Cars to Help Navigate Blind People," 2017 IEEE International Conference on Computer Vision Workshops (ICCVW), 2018, pp. 1424-1432, doi: 10.1109/ICCVW.2017.169

[53] B. Li, J. Pablo Muñoz, X. Rong et al., "Vision-based Mobile Indoor Assistive Navigation Aid for Blind People," IEEE Transactions on Mobile Computing, vol. 18, no. 3, pp. 702-714, 2019, doi: 10.1109/TMC.2018.2842751.

[54] A. Kumar, R. Patra, M. Manjunatha, J. Mukhopadhyay, and A. K. Majumdar, "An Electronic Travel Aid for Navigation of Visually Impaired Persons," 2011 Third International Conference on Communication Systems and Networks (COMSNETS 2011), 2011, pp. 1-5, DOI:10.1109/COMSNETS.2011.5716517.

[55] C. L. Lee, C. Y. Chen, P. C. Sung, and S. Y. Lu, "Assessment of a Simple Obstacle Detection Device for the Visually Impaired," Applied Ergonomics, vol. 45, no. 4, pp. 817-824, 2014, doi: 10.1016/j.apergo.2013.10.012.

[56] L. B. Neto, F. Grijalva, V. R. Margareth Lima Maike et al., "A Kinect-Based Wearable Face Recognition System to Aid Visually Impaired Users," IEEE Transactions on Human-Machine Systems, vol. 47, no. 1, pp. 52-64, 2017, doi: 10.1109/THMS.2016.2604367

[57] D. Rodriguez-losada and G. J. Lacey, "The Evolution of Guido; A Smart Walker for the Blind," IEEE Robotics \& Automation Magazine, vol. 15, no. 4, pp. 75-83, 2008, doi: 10.1109/MRA.2008.929924.

[58] J. Sánchez and M. Sáenz, "Metro Navigation for the Blind," Computers and Education, vol. 55, no. 3, pp. 970-981, 2010, doi: 10.1016/j.compedu.2010.04.008.

[59] H. Moshtael, T. Aslam, I. Underwood, and B. Dhillon, "High Tech Aids Low Vision: A Review of Image Processing for the Visually Impaired," Translational Vision Science \& Technology, vol. 4, no. 4, pp. 1-10, 2015, Art. no. 6, doi: 10.1167/tvst.4.4.6.

\section{BIOGRAPHIES OF AUTHORS}
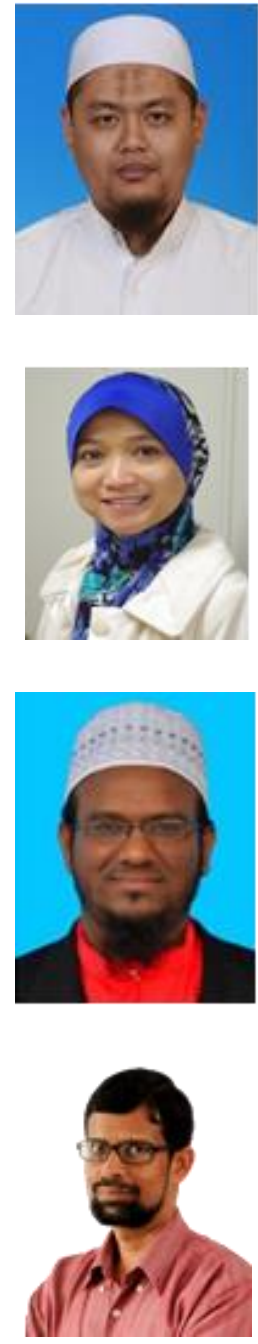

Muhammad Rabani Mohd Romlay received B.Eng (Hons) and M.Sc. degree in Mechatronics Engineering from International Islamic University Malaysia (IIUM) \& currently pursuing $\mathrm{Ph} . \mathrm{D}$ from the same instituition. The focus of his previous works includes neural network, data science, machine learning, rainfall-runoff, autonomous vehicle and navigation aids for the visually impaired people. Actively participating in conferences and exhibitions, he has received numerous awards which includes medallist in the IRIE 2014 and ORKID WEC 2017 and participation in KERICE 2019 and KERICE 2020. His current research area covers the field of machine learning, machine vision, artificial intelligent, autonomous robot, object recognition and identification and feature extraction.

Siti Fauziah Toha (B.Eng'03-M'06-PhD'10), is currently an Associate Professor at the Department of Mechatronics Engineering, International Islamic University Malaysia (IIUM). She completed her Ph.D in Automatic Control and Systems Engineering from The University of Sheffield. Her current research interest is battery management system, energy reduction for electric motorcycle development as well as hybrid renewable energy applications using computational intelligence methods such as Genetic Algorithms, Fuzzy Logic and Particle Swarm Optimization. She is also an active member of Young Scientist Network, Academy of Sciences Malaysia (YSN-ASM).

Azhar Mohd Ibrahim is an Assistant Professor at International Islamic University Malaysia (IIUM). He has completed his Ph.D. at the School of Computer Sciences, Universiti Sains Malaysia under research theme of crowd dynamics. His research focuses on evacuation models, reinforcement learning and remote sensing. He has published articles in reputed high impact journals (ACM TIST, Physica A and JASSS), executing several research grants and supervising $\mathrm{PhD}$ scholars. He has been receiving several honors including the recipient of the best student award for Master of Science by research, 29th IIUM convocation ceremony and the winner of the 3MT thesis competition held at the Computer Science Postgraduate Colloquium at Universiti Sains Malaysia in 2016.

Ibrahim Venkat is serving as an Associate Professor at the School of Computing and Informatics, Universiti Teknologi Brunei. He is also a Honorary Senior Research Fellow of the University of Kent. His research interests include evacuation models, computer vision, intelligent systems and bio-inspired computing. He has been contributing interesting articles in reputed journals (IJCV, IEEE and ACM), organized reputed conferences, executed several research grants and guided many $\mathrm{PhD}$ scholars. He has received numerous honors including the prestigious James-Watt Scholarship, Gold medals from Malaysian Education Ministry and Korea. 